\title{
Regimes de fronteira a "ilegalidade" migrante na América Latina e no Caribe
}

\section{Eduardo Domenech* Gustavo Dias**}

\section{Resumo}

Este artigo trata do estabelecimento de regimes de controle migratório e da proliferação de fronteiras na América Latina e no Caribe, no marco dos recentes processos contemporâneos de regionalização e internacionalização das políticas migratórias e de externalização das fronteiras. Especificamente, explora as reconfigurações que as políticas e práticas de controle de migração e fronteira têm experimentado durante as duas últimas décadas em contextos socio-históricos específicos. Inspirado nos estudos críticos sobre migração e fronteiras, e embasado em uma perspectiva multissituada e processual, o artigo privilegia alguns conflitos de fronteira que são significativos ou relevantes para compreender mutações que condensam processos mais amplos ou abrangentes nos regimes de controle fronteiriço da América Latina e do Caribe. Primero, o artigo aborda a relação entre o controle de fronteira e a "migração irregular", procurando analisar o surgimento de "crises" migratórias na região. Segundo, examina alguns componentes do regime de fronteira sulamericano, a partir da identificação de políticas e práticas de controle e contestação em torno do movimento. Finalmente, reconhece alguns aspectos característicos do regime fronteiriço norte-americano e centro-americano, ao mesmo tempo em que problematiza a conformação do México como "fronteira vertical" e o surgimento de novas formas de migração em um contexto de violência generalizada.

Palavras-chave: América Latina e Caribe, regime de fronteiras, crise migratória, luta migrante.

* Consejo Nacional de Investigaciones Científicas y Técnicas / Universidad Nacional de Córdoba, Córdoba, Argentina.

** Universidade Estadual de Montes Claros, Montes Claros, MG, Brasil. 


\section{Border regimes and migrant "illegality" in Latin America and the Caribbean}

\section{Abstract}

This article deals with the production of migration control regimes and the proliferation of borders in Latin America and the Caribbean, within the framework of the recent contemporary processes of regionalization and internationalization of migration policies and the externalization of borders. Specifically, it explores the reconfigurations that both migration and border control policies and practices have experienced over the past two decades in specific socio-historical contexts. Inspired by critical studies on migration and borders, and based on a multi-sited and processual perspective, the article focuses on some border conflicts that are relevant to understand mutations that condense broader or more comprehensive processes in the Latin American and Caribbean border control regimes. Firstly, the article addresses the relationship between border control and "irregular migration", seeking to analyse the emergence of migratory "crises" in the region. Secondly, it unfolds some components of the South American border regime, identifying contested control policies and practices on migrant movements. Finally, it recognizes some characteristic aspects of the North American and Central American border regime, while it problematizes the conformation of Mexico as a "vertical border" and the emergence of new forms of migration in a context of generalized violence.

Keywords: Latin America and the Caribbean, border regime, migration crisis, migrant struggle.

\section{Introdução}

ste artigo trata do estabelecimento de regimes de controle migratório
e da proliferação de fronteiras na América Latina e no Caribe, no
marco dos recentes processos contemporâneos de regionalização e internacionalização das políticas migratórias e de externalização das fronteiras. Especificamente, explora as reconfigurações que as políticas e práticas de controle de migração e fronteira têm experimentado durante as duas últimas décadas em contextos socio-históricos específicos. Por meio de uma perspectiva multissituada e processual, oferecemos uma leitura 
que permita apreciar as conexões existentes entre as diversas experiências nacionais em áreas de fronteira, bem como as articulações específicas que se estabelecem entre as diferentes práticas de controle e vigilância da mobilidade migratória e das fronteiras, em determinadas circunstâncias e momentos, na América Latina e no Caribe. Embora a análise proposta reconheça a importância da origem nacional dos migrantes nos sistemas de classificação estatais e nas práticas de migração e controle de fronteiras, nossa abordagem não considera o grupo nacional, necessariamente, como o ponto de partida. Antes, o vislumbramos dentro de um quadro mais amplo, em que sua relevância analítica é determinada por algum evento específico e pela implantação de certas políticas e práticas. Privilegiamos alguns conflitos de fronteira que são significativos ou relevantes para compreender mutações que condensam processos mais amplos ou abrangentes nos regimes de controle fronteiriço da América Latina e Caribe.

Do ponto de vista dos estudos críticos sobre migração e fronteiras que inspiram este artigo, o conceito de "regime de migração e fronteira" refere-se a um espaço de conflito, negociação e contestação entre vários atores que disputam a definição política da migração e da fronteira. Essa noção permite a incorporação de atores cujas práticas estão relacionadas, embora não estejam organizadas de acordo com uma lógica ou racionalidade central, ou seja, possibilita entender a regulação como um efeito das práticas sociais (Hess, 2012). Da mesma forma, um regime não responde a uma planificação consistente, deixa espaço para os interstícios, ambiguidades e tensões e é o resultado de um constante "trabalho de reparo" por meio de práticas (Sciortino, 2004). A partir dessa abordagem, a noção de "crise" no campo da migração e do refúgio não se reduz a uma anomalia ou situação temporária, mas é uma condição estrutural central para fronteiras (Mezzadra; Neilson, 2013; Hess; Kasparek, 2017). Avançar na compreensão dos regimes de fronteira é decisivo por seu impacto na hierarquização e estratificação internacional da mobilidade e por seus efeitos específicos sobre quem se desloca: moldam a vida dos migrantes, bem como a forma 
como estes produzem a sua mobilidade, por meio da seleção, obstrução e iminente risco de deportabilidade.

As lutas migrantes formam um elemento constitutivo dos regimes de migração e fronteiras. Não são meras respostas ou reações a políticas oficiais de migração ou a qualquer nova forma de governo da migração, mas sim têm um papel ativo na definição de políticas de controle de mobilidade (Papadopoulos; Stephenson; Tsianos, 2008). Essas políticas organizam-se com base no modo como são desafiadas pelas múltiplas formas e contínuas transformações que os movimentos migratórios e suas lutas derivadas adquirem em diferentes escalas. Como proposto por Mezzadra e Neilson (2013), as fronteiras são simultaneamente espaços de controle e espaços de excesso e, como tal, lugares de luta. As chamadas "lutas pelo movimento" (Papadopoulos; Tsianos 2013; Martignoni; Papadopoulos, 2014; Tazzioli, 2015) envolvem diferentes migrações e emergem no confronto com os regimes de controle da mobilidade. As lutas pelo movimento fazem parte das lutas fronteiriças: "a luta pelo movimento ou pela permanência é a mais elementar das lutas fronteiriças" (El-Shaarawi; Razsa, 2019, p. 17). A força desses movimentos espaciais, protagonizados por migrantes para disputar e transgredir - sem, necessariamente, uma intencionalidade política - os limites e formas estabelecidos e esperados para que as migrações sejam "seguras", "ordenadas" e "regulares", constitui um aspecto central das lutas pelo movimento.

Para a reconstrução dos processos, práticas e eventos de que tratamos neste artigo em relação à transformação da migração e do controle de fronteiras na América Latina e no Caribe, utilizamos fontes bibliográficas, jornalísticas e documentais audiovisuais de vários tipos: notas jornalísticas, documentos de trabalhos e anuários de organizações civis, declarações de grupos ou redes de organizações, comunicações institucionais, comunicados de imprensa oficiais, regulamentos nacionais e comunicações pessoais, testemunhos e intervenções públicas. Também utilizamos nosso próprio arquivo, que reúne material hemerográfico e documentos oficiais 
relacionados ao fechamento de fronteiras, detenções e expulsões em vários países latino-americanos.

O artigo está organizado em quatro seções: na primeira, abordamos a relação entre o controle de fronteira e a "migração irregular", procurando analisar o surgimento de "crises" migratórias na região; na segunda seção, examinamos alguns componentes do regime de fronteira sul-americano, a partir da identificação de políticas e práticas de controle e contestação em torno do movimento; na terceira seção, identificamos alguns aspectos característicos do regime fronteiriço norte-americano e centro-americano, ao mesmo tempo em que fazemos um relato da conformação do México como "fronteira vertical" e do surgimento de novas formas de migração em um contexto de violência generalizada; e, por fim, na quarta seção avançamos algumas reflexões finais sobre as singularidades dos regimes de fronteira na América Latina e no Caribe.

\section{Fronteiras, controle e migração "irregular": a produção das "crises migratórias"}

O final da década de 1990 revela profundas transformações políticas e, sobretudo, sociais na América Latina. A partir da ascensão de Hugo Chávez na Venezuela, em 1999, a região experimentou o avanço de governos de centro-esquerda e esquerda que, apesar de suas disparidades e contradições, foram considerados "progressistas" ou "neodesenvolvimentistas". Chegaram ao poder, gradualmente, por meio de eleições que refletiam inúmeras lutas e reivindicações populares contra governos que, desde o início da década, estiveram alinhados à política econômica "que se convencionou chamar de padrão neoliberal de desenvolvimento" e que contou com o estabelecimento de um conjunto de políticas públicas duras e antipopulares no âmbito do Consenso de Washington (Martins, 2013, p. 313). Em geral, trata-se de novos governos que "asumieron la tarea de intentar enfrentar las limitaciones del proyecto hegemónico del neoliberalismo en crisis en la región" (Féliz; Pinassi, 2017, p. 9). Em decorrência, as transformações apareceram em 
ritmo e intensidade diferentes. Governos como, por exemplo, os de Evo Morales e Rafael Correa propuseram constituições bastante arrojadas e inclusivas. Todavia, em outros países, como Brasil e Argentina, registrouse a ascensão eleitoral de forças políticas que se apresentaram como antineoliberais, mas que, contudo, não produziram rupturas drásticas nem dramáticas no sistema político, no mercado financeiro ou no domínio de elites nacionais (Zibechi; Machado, 2017, p. 13). Logo, questionamentos críticos sobre as reais mudanças estruturais vividas na região e o impacto prático que elas trariam para populações que, historicamente, vivem sob condições de vulnerabilidade, foram sistematicamente abafados. Isso, em parte, ocorreu por conta do otimismo trazido pelo crescimento econômico temporário e o forte hedonismo consumista que se espraiou entre as classes médias e populares durante toda a primeira década de 2000 e início da seguinte (Singer, 2012).

O aprofundamento da reprimarização da pauta exportadora incentivada pela projeção chinesa na economia mundial, aliado à forte hegemonia do setor financeiro, impôs dura limitação ao desenvolvimento industrial e, sobretudo, técnico-científico (Katz, 2016; Pinassi, 2017). Ainda assim, a América Latina alcançou consideráveis taxas de crescimento econômico e redução inédita de pobreza e extrema pobreza - mas não da acentuada desigualdade - desde o início dos anos 2000. Presenciamos parcela significativa da receita pública ser revertida para importantes políticas redistributivas, além da integração de amplas parcelas da população aos mercados de consumo (Leite; Uemura; Siqueira, 2018).

Diante desse relativo otimismo, a América Latina passou a figurar de forma significativa nas rotas migratórias internacionais, ademais de ver um considerável crescimento e reconfiguração da já estabelecida migração intrarregional. O crescimento econômico regional, aliado ao quadro de pleno emprego e de políticas sociais de combate à pobreza, foram importantes atrativos para intensificar a já presente migração regional e internacional na América Latina e no Caribe (Granja; Villarreal, 2017). Por outra parte, grupos migratórios que, por conta do forte legado colonial, mantêm rotas 
de migração para países europeus, por exemplo, tornaram-se presentes também na região. Durante a última década, registrou-se um aumento das chegadas e uma diversificação das origens nacionais dos migrantes oriundos de países africanos e asiáticos. O crescimento substancial desses grupos migratórios respondeu, em boa medida, ao processo de reforço de fronteiras produzidos no Atlântico Norte. Políticas migratórias restritivas e o emprego de um forte aparato tecnológico bélico nas fronteiras da União Europeia e dos Estados Unidos, sobretudo na década de 2000, afetaram diretamente os deslocamentos migratórios oriundos da América Latina, Caribe, África e Ásia para esses dois locais (Mezzadra; Neilson, 2013; Dias, 2016).

Em pouco menos de vinte anos, esse "giro à esquerda" regional demonstrou-se frágil em reformas ou rupturas capazes de assegurar o reconhecimento de direitos políticos de populações historicamente marginalizadas pelas elites nacionais. Dentre essas, aquelas suscetíveis à condição migratória, que seguiram sendo entendidas como trabalhadoras e, portanto, sujeitas ao intenso controle estatal, destituídas de amplos direitos políticos e marcadas pelo estigma da temporariedade. O quadro ganha maior dramaticidade com a recente "virada à direita", resultante de rupturas - em alguns casos, através de golpes políticos com forte presença de interesses internacionais - das alianças políticas firmadas entre governos progressistas e setores conservadores, durante o curto boom das commodities na região.

As duas últimas décadas mostram uma intensificação dos processos de criminalização da migração e securitização de fronteiras em escala global na América Latina. Na América do Sul, esses processos generalizaram-se nos últimos dez anos, como resultado do deslocamento sofrido pelas políticas baseadas na expansão e proteção dos direitos da população migrante e no ressurgimento da violência do Estado. A conjunção de reformas migratórias implementadas por alguns governos nacionais da América do Sul, a mutação e intensificação do controle de fronteiras no hemisfério norte, somadas à chegada e expansão de novos contingentes migratórios, produziram conexões inter-regionais e intercontinentais que tiveram múltiplos efeitos na ordem fronteiriça regional. Assim, espaços 
geopolíticos que durante os primeiros anos do século XXI se estabeleceram como zonas de fronteira com relativa independência foram acoplados por meio das práticas de terceirização da fronteira dos Estados Unidos, da formação de um corredor migratório que articula Equador, México e Estados Unidos e da reconfiguração do Equador como um "país de trânsito" (Álvarez Velasco, 2019; 2020). As novas migrações oriundas de países caribenhos, africanos e asiáticos, que não se conformavam aos parâmetros de legalidade estabelecidos pelos estados, perturbaram a ordem fronteiriça regional e deram origem a diferentes práticas institucionais de controle do movimento. Presenciou-se uma escalada de eventos que transformou o espaço latino-americano, como se poderá ver com maior cuidado adiante, em diferentes zonas de fronteira que perpassam centros decisórios no Atlântico Norte (Márquez Covarrubias, 2015; Dias, 2016; Cordero; Mezzadra; Varela Huerta, 2019).

Desde a entrada em vigor da isenção de visto no Equador, em 2008, as turbulências geradas pela imigração de vários países asiáticos e africanos, bem como do Caribe, especialmente do Haiti e de Cuba, perturbaram os arranjos institucionais voltados ao controle da migração e fronteiras. Esses movimentos, rapidamente, tornaram-se uma questão de interesse regional quando as burocracias nacionais e internacionais começaram a perceber sua expansão e seu caráter "irregular". Em 2010, precisamente, a Organização dos Estados Americanos (OEA) se organizou em sua sede em Washington para debater o tema, por meio do workshop "Migração extracontinental nas Américas", com a participação de funcionários governamentais e organizações internacionais. A realização desse evento prenunciou a abertura de um novo ciclo de migração e controle de fronteiras em nível regional. A chegada desses migrantes, tanto por sua magnitude quanto por suas características, foi considerada um fenômeno migratório novo e recente na região (OEA, 2010). Nessa nova etapa, como revelariam os conflitos fronteiriços ocorridos nos anos seguintes, as estratégias de mobilidade dos migrantes "irregulares" considerados "extracontinentais" ou "extrarregionais" modificaram as políticas de controle multilateral. 
Entre as diferentes situações de "crise" desencadeadas na região latino-americana em torno da migração "irregular", uma das mais notáveis teve origem nos sucessivos fechamentos de fronteiras determinados pelos Estados centro-americanos ao longo de 2015, com o intuito de conter, fundamentalmente, o êxodo de cubanos. O crescimento exponencial da chegada de migrantes cubanos à fronteira sul dos Estados Unidos, desde a reforma migratória de Cuba, no início de 2013, que eliminou a autorização de saída e ampliou o tempo de permanência fora da ilha, favoreceu o restabelecimento das relações diplomáticas entre os Estados Unidos e Cuba em 2015. Este fato levou os habitantes cubanos da ilha a especularem sobre o fim da política estadunidense denominada "pés secos, pés molhados", instituída em 1995, após a "crise dos balseiros". Consequentemente, a emigração internacional cubana se intensificou significativamente. Por outro lado, nesse mesmo ano, o governo equatoriano deixou de solicitar a cartaconvite como requisito para a concessão do visto aos cidadãos cubanos e o Equador passou a oferecer maiores possibilidades como local de entrada no continente, transformando e mudando a dinâmica das rotas migratórias.

Os diversos conflitos fronteiriços decorrentes do surgimento de novos movimentos e travessias de fronteiras associados à "irregularidade" foram representados como "crises migratórias" ou "crises humanitárias" por uma multiplicidade de atores que fazem parte da infraestrutura do controle de mobilidade. A sequência de intervenções institucionais passou pela aplicação de medidas para facilitar, conter e reprimir a circulação fronteiriça e prevenir novas chegadas. As tensões e reclamações derivadas da imobilidade produzida pelos sucessivos fechamentos de fronteira na Nicarágua, Costa Rica e Panamá foram dissipadas, em primeira instância, por meio da aplicação de vistos humanitários (ou "salvo-conduto") e pontes aéreas, com o auxílio da Organização Internacional para as Migrações (OIM), para o México. Tal ação contou, ainda, com a realização de reuniões intergovernamentais especiais. Assim, a produção oficial de um "corredor humanitário" possibilitou a mobilidade sujeita a autorizações de trânsito e acordos diplomáticos firmados entre estados e com a participação de 
organizações internacionais. Posteriormente, a persistência do movimento migratório foi confrontada com novas negociações bilaterais e ações punitivas. Depois que México e Cuba estabeleceram um acordo para que migrantes cubanos deixassem de receber salvo-condutos, o Estado mexicano passou a realizar deportações de cubanos "indocumentados" por meio de rotas terrestres e marítimas. Os conflitos internacionais gerados pelo fechamento das fronteiras e pela privação de movimento de milhares de migrantes cubanos, haitianos, africanos e asiáticos em países da América Central envolveram negociações diplomáticas que culminaram no reestabelecimento da obrigatoriedade de visto para cidadãos cubanos no Equador. A persistência de conflitos fronteiriços também levou os governos colombiano e equatoriano a assinarem em poucos meses um protocolo pelo qual buscavam chegar a um consenso sobre a inadmissibilidade e o procedimento de deportação de estrangeiros de terceiros países sob a narrativa do combate ao contrabando de migrantes.

Já codificados em termos de "crises", esses eventos fronteiriços serviram de base para ativar mecanismos de controle da "migração irregular" no quadro de esquemas de ação e pensamento associados à "governação dos fluxos migratórios". A questão da "migração irregular" foi trazida aos espaços intergovernamentais regionais com significativa interferência do governo dos Estados Unidos e se transformou em objeto de produção de conhecimento especializado para orientar e legitimar as ações dos Estados. Em 2016, o Conselho Permanente da OEA acatou o pedido de "estudo urgente da situação migratória na região" apresentado por representantes do Estado da Costa Rica à Secretaria Geral da organização. Este pedido respondeu ao "recente aumento do fluxo de migrantes em situação de migração irregular" de países da África, Ásia e Caribe, em particular Cuba e Haiti. O relatório regional solicitado foi preparado com base em um acordo com a OIM (OEA/OIM, 2016). Nesse mesmo ano, a OIM (2016) publicou um plano para "fortalecer a governança dos fluxos migrantes extrarregionais na Mesoamérica" com o objetivo de oferecer um guia que servisse de apoio aos Estados para responder à "migração irregular" classificada de acordo 
com sua origem regional ou nacional: migrantes extrarregionais da Ásia e África, migrantes cubanos e migrantes haitianos (OEA/OIM, 2016). Os diversos "fluxos migratórios" de carácter "extrarregional" foram objetos de relatórios periódicos e documentos de política que dão conta da sua magnitude, crescimento e distribuição espacial.

Outra das "crises", que envolveu movimentos de larga escala e teve alcance regional, ocorreu no contexto da saída massiva de venezuelanos iniciada por volta de 2015. A expansão acelerada e a alta visibilidade do movimento fronteiriço de venezuelanos em certos contextos nacionais criaram condições para que fosse representada como uma crise migratória e humanitária por diversos atores estatais e não estatais interessados em enfraquecer e deslegitimar o governo nacional da Venezuela ${ }^{1}$. A produção de uma "crise migratória" venezuelana constituiu um cenário propício para a legitimação da intervenção de múltiplas agências internacionais, entre elas as organizações intergovernamentais das Nações Unidas especializadas em refugiados e migração. O chamado "êxodo venezuelano" colocou a questão do refúgio e dos refugiados entre as questões políticas de maior discussão regional, além de adquirir visibilidade internacional ao ser tematizado e abordado como um "deslocamento populacional em grande escala". Esse contexto permitiu uma expansão acentuada do Alto Comissariado das Nações Unidas para os Refugiados (ACNUR) e um fortalecimento significativo de suas atividades na região. O movimento massivo de venezuelanos estimulou a construção de uma "resposta regional", além das medidas estatais realizadas de forma independente e errática. O Grupo de Lima, criado em 2017 e composto por representantes de diversos Estados das Américas, passou a representar a posição regional sobre migração e refúgio dos novos governos da nova direita ${ }^{2}$. Por meio do documento conhecido como Declaração de Lima, o grupo propôs "abordar a crítica situação da

\footnotetext{
1Ramírez et al. (2019) identificam três posições políticas sobre a emigração venezuelana: i) como um reflexo da crise interna expressa como crise humanitária; ii) representando uma crise regional de emergência; e iii) a negação e o desconhecimento da crise migratória.

${ }^{2}$ Apesar de os Estados Unidos não fazerem, oficialmente, parte do grupo, o acompanham por meio da participação do Secretário de Estado dos Estados Unidos e ex-diretor da Agência Central de Inteligência (CIA), Mike Pompeo.
} 
Venezuela e explorar formas de contribuir para a restauração da democracia naquele país através de uma saída pacífica e negociada". Assim, apoiaram "a inclusão da crise de migrantes e refugiados da Venezuela, pela primeira vez, no Apelo Humanitário Global da ONU para 2019, bem como a nomeação do representante conjunto da OIM e do ACNUR" (MRE, 2019).

Em linhas gerais, diante do deslocamento massivo de venezuelanos, as diferentes organizações burocráticas de controle migratório têm desenvolvido ações que respondem tanto às circunstâncias do respectivo contexto nacional como às negociações em nível regional. Ao contrário do que aconteceu com migrantes haitianos e senegaleses, outros dois grupos com intensa circulação na região, os venezuelanos foram favorecidos com diferentes medidas destinadas a facilitar seu trânsito ou residência sob o argumento humanitário. Esse tratamento favorável está relacionado às tensões e confrontos internacionais que vários governos que personificam a "virada à direita" na região sulamericana têm mantido com o governo venezuelano. As solicitações para o reconhecimento da condição de refugiado por cidadãos venezuelanos fazem parte dessa situação. As diferentes ações de governos e organizações internacionais voltadas para o reconhecimento da condição de refugiado dos migrantes venezuelanos são uma manifestação clara do uso histórico das políticas de refúgio como instrumento de políticas externas (Zolberg; Suhrke; Aguayo, 1986). Em alguns países, como o Brasil, medidas têm sido implementadas para dificultar a circulação de pessoas, seu assentamento e sua distribuição no território nacional desde a intensificação da migração em 2016 (Gandini; Pietro; Lozano, 2019). Em 2018, o governo brasileiro iniciou, apelando ao discurso humanitário e de ordenamento, um "programa de internalização". A ação, conhecida como "Operação Acolhida"3, contou com a presença do exército brasileiro - principal responsável por essa atuação - da ONU e de entidades civis.

\footnotetext{
${ }^{3}$ Segundo o site da própria operação (https://www.gov.br/acolhida/historico/), ela segue três pilares de atuação. O primeiro compreende o ordenamento da fronteira brasileira com a Venezuela por meio do controle e vistoria de documentos e vacinação de migrantes. $\mathrm{O}$ segundo pilar é o próprio acolhimento. Ele se dá através da oferta de abrigo, alimentação e cuidados médicos. O terceiro e último pilar compreende a interiorização de migrantes e refugiados venezuelanos do estado de Roraima para outros estados brasileiros com objetivo de inclusão socioeconômica.
} 


\section{O regime de fronteira sul-americano}

Na América do Sul, a formação de um regime de migração e fronteiras implicou a produção de um "espaço sul-americano", entendido como zona de fronteira (Domenech, 2019). Tal zona fronteiriça é produto de processos e mecanismos de regionalização e internacionalização da migração e das políticas de fronteira que ocorreram no momento da chamada "globalização do controle migratório" (Düvell, 2015) e do estabelecimento de um "regime de controle global da migração" (Mezzadra, 2005), agora sob a hegemonia do modelo tecnocrático de "governança global" da migração. A existência de um regime de controle migratório global é sustentada por distintos processos de regionalização e internacionalização de "políticas migratórias" que envolvem atores que operam em diferentes escalas. Os chamados Processos Consultivos Regionais (PCRs), promovidos em diferentes partes do mundo, têm sido uma ferramenta fundamental na configuração do regime de controle migratório global. Eles fazem parte da nova arquitetura de regulação internacional dos movimentos migratórios denominada "governança global" e que se baseia na cooperação interestatal. Portanto, esses processos consultivos regionais e sua adoção na região, como a Conferência Sul-Americana de Migração, bem como processos de integração regional, como o Acordo de Residência do Mercosul, tiveram efeitos muito concretos na formação do espaço sul-americano como zona de fronteira. Ao mesmo tempo, diferentes redes e organizações de migrantes começaram a construir relações e espaços internacionais para compartilhar suas experiências e preocupações, assim como publicizar suas reivindicações, assumindo a regulamentação da migração como uma questão regional (Domenech; Boito, 2019).

A intensificação da imigração e do controle de fronteiras no espaço sulamericano teve uma de suas principais expressões no aumento e ampliação do uso de medidas punitivas ou repressivas como detenção, expulsão e rejeições na fronteira. Essas práticas de violência estatal, como veremos a seguir, estão entrelaçadas com outras medidas de controle e contenção 
da migração, tais como o aumento das exigências de entrada, a imposição de vistos consulares e humanitários, a negação do estatuto de refugiado e o desenvolvimento de programas de "regresso voluntário", entre outros. Desde 2015, os números oficiais de expulsões, ordens de expulsão e inadmissões apontavam para dois padrões migratórios dominantes na região sul-americana: um predomínio da migração intrarregional e o fato de o maior número de estrangeiros expulsos ser de países vizinhos. A Colômbia constituiu, em certa medida, uma exceção, já que os cubanos foram, em geral, o grupo nacional mais afetado pelas medidas punitivas. Entre os grupos nacionais predominantes nas estatísticas de inadmissões e expulsões em nível regional, além de estrangeiros de países vizinhos, estavam cidadãos chineses, cubanos, haitianos e dominicanos (Domenech, 2015). Vistos à distância, esses números são a expressão da transformação por que passa o regime migratório regional e fronteiriço desde a entrada em vigor da isenção de visto no Equador.

Estudos mais recentes sobre os processos e práticas de criminalização migratória mostram as mudanças ocorridas nos últimos anos no campo do controle punitivo da migração. O artigo de Ramos, Dufraix e Quinteros (2020), incluso neste dossiê, foca no impacto da imposição do visto consular, no Chile, durante a gestão de Sebastián Piñera, em 2018, para migrantes oriundos da Venezuela, do Haiti e da República Dominicana, nas três regiões administrativas ao norte do país (Arica e Parinacota, Tarapacá e Antofagasta). Tal imposição não apenas restringiu a mobilidade desses grupos, como lançou à condição de irregularidade milhares que já se encontravam dentro do país. Uma vez criminalizados pelo Estado chileno por conta do status legal precarizado, tornam-se simultaneamente "não cidadãos" passíveis de expulsão e mão de obra precária e barata passível de exploração laboral. Em outros espaços nacionais onde a migração foi afetada pelo endurecimento da política de imigração, como, por exemplo, a Argentina, a expulsão de "estrangeiros criminosos" foi a ação estatal central na produção de uma "política de hostilidade" contra imigrantes (Domenech, 2020). Nesse contexto, depois que a criação de um centro de detenção 
para migrantes com ordem de expulsão desmoronou devido às mobilizações ativistas migrantes, o governo nacional ordenou, por meio de um Decreto de Necessidade e Urgência (DNU), no início de 2017, a alteração da Lei de Migração sancionada no final de 2003, com o objetivo de reforçar elementos punitivos contidos no regulamento. Com essa medida, conforme apontado por Basok (2019), o governo mobilizou a narrativa da "crise" de segurança para justificar o fortalecimento do controle e das medidas punitivas previstas no DNU. Como em outros contextos nacionais nos quais a questão da imigração esteve envolvida em processos de securitização, na Argentina, o DNU representou o obscurecimento entre o direito de imigração e o direito penal (Domenech, 2020).

Ainda em outros contextos nacionais, a violência estatal, perpetrada por meio de práticas como detenção e expulsão, tem sido utilizada em conflitos sociais derivados das "lutas de fronteira" que se desenvolveram na região. Em meados de 2016, na cidade de Quito, Equador, um grande grupo de cubanos protagonizou uma das lutas de fronteira - especificamente entendida em termos de "lutas pelo movimento" - que condensou, de forma exemplar, um conflito de fronteira derivado dos atritos entre a intensidade da mobilidade fronteiriça e a vontade de contê-lo. Consistia, especificamente, em uma ação coletiva direcionada à Embaixada do México para obter um salvo-conduto que lhes permitisse continuar a jornada migratória e, assim, alcançar a fronteira estadunidense. A ocupação do espaço público, enquanto forma de protesto, ocasionou sucessivos despejos realizados pela polícia equatoriana. Um deles, em particular, contou com o caráter espetacular de intervenção militarizada, detenções e deportações. Essa violência institucional ativou várias formas de protesto, solidificou alianças e construiu redes de apoio e solidariedade entre migrantes e ativistas de vários tipos. Uma das manifestações mais claras foi a formação do Coletivo Atopia, composto por advogados de direitos humanos e investigadores em questões de imigração e que surgiu, precisamente, em resposta aos eventos de detenção e deportação ocorridos. Ao mesmo tempo, essa experiência de sofrimento coletivo, junto com a precariedade das condições de vida em um 
contexto de crise econômica, impulsionou o movimento mesmo daqueles que até aquele momento não haviam pensado em deixar o Equador para fazer o caminho para o norte (Álvarez Velasco, 2019; Correa, 2019). Alguns anos depois, novamente em Quito, aconteceu outro evento relacionado às "lutas pelo movimento": desta vez, um grupo de famílias de refugiados colombianos e requerentes de asilo ocupou o espaço público para reclamar ao ACNUR seu reassentamento ou transferência para o Canadá ou, então, para países da União Europeia. Após algumas semanas, os manifestantes e suas famílias foram despejados do local e dispersos em acomodações precárias nas regiões norte e sul da cidade.

No espaço sul-americano também houve uma renovação nos usos e fundamentos das práticas de visto. A imposição de um visto consular para impedir o movimento dos locais de origem e reduzir a chegada de migrantes "indesejáveis", bem como o estabelecimento de um "visto humanitário" para facilitar a entrada ou evitar a concessão do estatuto de refugiado a certos grupos nacionais têm ações recorrentes nos últimos anos. A imposição do visto consular, enquanto estratégia para conter e impedir novas chegadas, afetou principalmente cidadãos da República Dominicana, Haiti e Senegal. Em 2012, Chile e Argentina estabeleceram um visto consular para cidadãos dominicanos sob o argumento de combate ao tráfico e contrabando de pessoas. Até finais de 2015, o governo equatoriano restabeleceu o visto para senegaleses, depois que o país funcionou como um "nó articulador" na América do Sul para essa população que não tinha visto consular brasileiro e argentino, mas queria chegar a tais países (Ménard Marleau, 2017). No caso dos haitianos, após o tratamento administrativo "humanitário" que receberam durante os anos após o terremoto, vários países sul-americanos passaram a exigir o visto consular ou algum outro tipo de documentação para validar seu status de "turista". No Peru, os cidadãos haitianos foram excluídos da isenção de visto de turista em 2012. O decreto supremo não forneceu outros fundamentos (ele apenas menciona "razões da política de imigração"), mas a imposição do visto estava relacionada às ansiedades das autoridades políticas e administrativas de controle de imigração, geradas 
pela constante entrada de haitianos procedentes do Equador e que viajavam rumo ao Brasil. Ademais, em 2011, ocorreu um acontecimento particular que motivou a medida: a "crise humanitária" vivida em um povoado da selva peruana devido à precária situação em que se encontravam as famílias haitianas que ali se encontravam retidas.

Em geral, as novas políticas de vistos foram desenvolvidas e legitimadas no quadro do humanitarismo e da proteção das vítimas do crime organizado. Em 2013, o governo equatoriano estabeleceu uma carta-convite como requisito para que os haitianos entrassem e permanecessem no país por até noventa dias, mas, por fim, a medida foi revertida (Ceja, 2015). No entanto, alguns anos depois, o país exigiu que os cidadãos haitianos se registrassem e preenchessem um "formulário de validação turístico exclusivo". A medida justificava-se em termos de proteção: o novo procedimento pretendia apenas "garantir a segurança e o respeito pelos direitos humanos" e evitar que fossem vítimas do tráfico de seres humanos. Em 2018, após um período que concentrou um grande número de rejeições em aeroportos internacionais, os governos chileno e argentino passaram a exigir vistos consulares de cidadãos haitianos quase que simultaneamente, sob uma narrativa humanitária de proteção à população migrante (Trabalón, 2018). Como medida complementar ao visto consular, o governo chileno organizou, com o apoio da OIM, um "plano humanitário de retorno ordenado" voltado especificamente aos migrantes haitianos ilegalizados. Esta ação foi motivada pelo "interesse nacional em proporcionar ao país uma migração ordenada, segura e regular" de uma "perspectiva global de governança da migração" ${ }^{4}$

Por outro lado, a dispersão da emigração venezuelana no espaço sulamericano, especialmente a partir de 2015, por exemplo, evidenciou o caráter mutante e contingente das medidas de regulação do movimento. Após um breve período sem a exigência de visto e/ou passaporte e o início das ações regionais, as autoridades nacionais encarregadas de assuntos migratórios dos principais países que recebem a migração venezuelana

${ }^{4}$ Resolução no 5.744, Ministério do Interior e da Segurança Pública, Santiago do Chile, 16 de outubro de 2018. 
decidiram começar a limitar as "facilidades" oferecidas e passaram, então, a estabelecer certas restrições de uma forma unilateral e errática. Entre eles, destacam-se a concessão de autorização de residência temporária, a obrigatoriedade de passaporte válido sem a admissão de carteira de identidade, a solicitação de certidão de antecedentes criminais e a exigência de visto humanitário ou especial (Acosta; Blouin; Freier, 2019). O estabelecimento de novos requisitos resultou em inadmissões e longas esperas nos pontos de fronteira para obtenção da documentação exigida. Em alguns países, como por exemplo o Peru, em 2019, diante das fortes restrições de entrada, alguns grupos de venezuelanos rapidamente se tornaram alvo de deportações. Por ocasião de um dos voos de deportação, o Ministro do Interior declarou que as expulsões realizadas faziam parte do projeto do Plano Migratório 2019, que visa a "garantir a migração venezuelana segura e ordenada para a população peruana".

O caso brasileiro é outro exemplo que, de forma exemplar, demonstra as diversas formas adquiridas pelo visto diante da chegada e presença de migrantes haitianos e venezuelanos nas áreas de fronteira. Pela fronteira amazônica brasileira entraram no Brasil os mais numerosos grupos migratórios oriundos do Caribe, América do Sul e África. Devido à negação do visto ou demora na emissão pela embaixada brasileira em Porto Príncipe, muitos dos migrantes haitianos que chegaram ao território brasileiro no período entre o terremoto de 2010 e a Copa do Mundo de 2014 buscaram entrar no país por meio do pedido de status de refugiado na fronteira amazônica. As cidades de Assis Brasil e Brasiléia, no Acre, por exemplo, estiveram entre as principais portas de entrada até 2012. Segundo Sidney Silva (2015), essas cidades fronteiriças estavam próximas de Epitaciolândia, onde há um escritório da Polícia Federal que aceitava pedidos de refúgio. Como Dias, Jarochinski Silva e Silva (2020, p. 10) demonstram, uma vez portando esse status regular, os migrantes estavam "aptos a obter permissão de trabalho e um cartão de registro de contribuinte (CPF) que lhes permitiria realizar transações econômicas formais". Todavia, a solicitação de refúgio como meio de regularização no Brasil não durou muito tempo. Dado o grande 
número de solicitações, o governo brasileiro entendeu que isso poderia comprometer sua imagem de liderança na Missão de Paz das Nações Unidas no Haiti (MINUSTAH), pois reconhecer a situação dos haitianos como de grave e generalizada violação de direitos humanos seria atestar o fracasso da operação. Assim, em 2012, o governo brasileiro, através do Conselho Nacional de Imigração (CNIG), instituiu a Resolução Normativa n 97 que criou o visto humanitário ${ }^{5}$ com uma cota de até 100 vistos mensais, que deveriam ser expedidos, ainda, em território haitiano (Silva, 2015). Tal medida causou um duro impacto sobre as já estabelecidas rotas migratórias haitianas que acessavam o território brasileiro através de um corredor conectando Haiti, Panamá, Equador, Peru e, em alguns casos, a Bolívia (Dias; Jarochinski Silva; Silva, 2020). Sem esse visto humanitário, esses migrantes em trânsito se encontram em condição de profundo deslocamento ${ }^{6}$. Eles não poderiam retornar ao Haiti ou aos países de passagem, pois sua autorização de trânsito já havia expirado, e nem almejar a regularização em território brasileiro ${ }^{7}$.

A negação sistemática do estatuto de refugiado a certos grupos nacionais, através de procedimentos sumários, é outra manifestação recente das formas em que as práticas migratórias e de controle das fronteiras são exercidas na região, face às estratégias de mobilidade "irregular" dos migrantes. Os migrantes senegaleses têm sido um dos grupos nacionais mais afetados pelos mecanismos de seletividade de refugiados. Dadas as dificuldades de obtenção do assentamento, essa população encontrou

\footnotetext{
${ }^{5}$ Todavia, essa cota logo foi revogada pela Resolução Normativa n ${ }^{\circ} 102$ de 24 de março de 2013.

${ }^{6} \mathrm{O}$ visto humanitário, apesar de facilitar a regularização e justificar sua existência em nome de uma suposta "segurança" e "proteção" dos migrantes, ainda é um visto excepcional e oferece menos proteção do que os ditames estabelecidos na nova lei de migração e o estatuto dos refugiados. Trata-se de um visto com limitações jurídicas e que confere ao migrante um status de temporariedade. Em outras palavras, uma forma de proteção reativa, que possibilita ao estado brasileiro evitar conceder o status de refugiado, regido pela Convenção de Genebra de 1951 e pela Declaração de Cartagena de 1984, e amparado por outros instrumentos internacionais.

${ }^{7}$ Cabe destacar que o visto humanitário foi desenvolvido exclusivamente para haitianos. Assim, migrantes oriundos de países como Senegal ou Gana não foram contemplados por medidas semelhantes.
} 
na figura do refúgio uma forma de aceder à documentação que thes permitisse, pelo menos temporariamente, trabalhar e circular livremente. Essa estratégia foi alertada pelas autoridades estatais encarregadas das organizações públicas de assistência a refugiados. Por exemplo, na reunião sobre migração extracontinental nas Américas organizada pela OEA e pela OIM em 2010, o funcionário estatal argentino exemplificou, por meio da migração senegalesa, as experiências e o aprendizado institucional para fortalecer "as capacidades de resposta a situações complexas e novas" (OEA, 2010). De acordo com o ponto de vista das autoridades, os pedidos de refúgio por migrantes senegaleses tornaram-se um fardo extraordinário para o sistema de proteção. Para essas autoridades, os senegaleses abusaram da figura do refúgio, pois, segundo os parâmetros do ACNUR, não necessitavam de proteção internacional, e prejudicavam a atenção a quem seria verdadeiramente merecedor do estatuto de refugiado. Perante tal situação, procuraram implementar diferentes medidas de dissuasão para contrapor a estratégia desenvolvida pelos migrantes senegaleses. $\mathrm{O}$ resultado obtido foi considerado um sucesso: uma redução acentuada nas solicitações de refugiados. Cerca de três anos depois, o Estado argentino iniciou um processo de regularização migratória voltado especificamente para os senegaleses, medida que resolveu temporariamente suas questões de residência e favoreceu apenas aqueles que estavam incluídos na delimitação temporária estabelecida pelo plano oficial (Zubrzycki, 2017).

\section{O regime de fronteira das Américas do Norte e Central}

O processo de regionalização da política migratória nas Américas do Norte e Central ganhou impulso decisivo na década de 1990, com a formação dos Processos Consultivos Regionais de Migração. Pouco depois da entrada em vigor do Acordo de Livre Comércio da América do Norte (NAFTA) e da celebração da Conferência Internacional sobre População e Desenvolvimento no Cairo, em 1994, foi criada a Conferência Regional sobre Migração (CRM) ou Processo Puebla, com a participação de representantes dos governos 
de Belize, Canadá, Costa Rica, El Salvador, Estados Unidos, Guatemala, Honduras, México, Nicarágua, Panamá e República Dominicana ${ }^{8}$. Essa iniciativa, como aponta Kron (2012), fazia parte do arranjo institucional do regime migratório e fronteiriço que foi estabelecido na América do Norte e Central com o objetivo de tratar a migração transfronteiriça como uma questão regional e multilateral. Além disso, esse novo regime regional desempenhou um papel central na reformulação da migração como um problema de segurança pública para a região (Kron, 2012). Desde o seu momento de fundação, esse espaço intergovernamental explicitou a adesão aos postulados básicos da gestão migratória, como o promovido pela OIM, que estabelece a migração ordenada como um "fenómeno benéfico con ventajas potenciales tanto para los países de origen como para los países de destino" (CRM, 1996).

O Processo de Puebla surgiu em um contexto caracterizado pelo crescimento e mudanças vividos pelos movimentos migratórios do México e da América Central para os Estados Unidos e Canadá entre as décadas de 1980 e 1990. A década de 1990, em particular, foi um período em que a região centro-americana se tornou um espaço de trânsito para migrantes da América do Sul, África, Ásia e Europa Oriental. Conforme evidenciado pelo relato pessoal de um funcionário do governo mexicano que participou da criação da CRM, a migração extrarregional foi "uma das questões mais conflitantes na agenda de migração regional" (Mohar, 2001, p. 264). No âmbito do plano de ação aprovado na reunião de 1997, no Panamá, os governos solicitaram à OIM para elaborar uma proposta que incluísse atividades e possíveis soluções operacionais para o tráfico de pessoas e a migração extrarregional. Na reunião realizada no ano seguinte, em Ottawa, a OIM apresentou o projeto da referida proposta e o tema foi novamente discutido na reunião realizada em El Salvador.

Desde o comunicado conjunto que resultou da primeira Conferência Regional sobre Migração (Puebla, 13 e 14 de março de 1996), os Estados

${ }^{8}$ Existem poucas análises críticas sobre o desenvolvimento institucional da Conferência Regional sobre Migração ou Processo de Puebla. Ver Kron (2011; 2012) e Ramírez; Ceja; Alfaro (2019). 
destacaram a necessidade de "controlar os fluxos de migrantes extrarregionais sem documentos". A produção da "migração irregular" como objeto de controle esteve indissociavelmente ligada à migração extrarregional, assim como se referiu aos "fluxos migratórios" associados à "irregularidade". Como em outros eventos intergovernamentais regionais, como vimos nas seções anteriores, na reunião realizada em Tapachula, México, em 2010, o aumento dos "fluxos migratórios extrarregionais" foi destacado entre as preocupações dos representantes dos Estados membros (Ramírez; Ceja; Alfaro, 2019). Mais uma vez, os governos nacionais solicitaram ao ACNUR e à OIM que elaborassem uma proposta capaz de fortalecer as respostas institucionais a esses movimentos migratórios (Declaração da XV CRM, 2010). Na reunião seguinte, concordaram em criar um Grupo de Trabalho ad hoc, coordenado por El Salvador e México, para tratar do tema "fluxos migratórios extracontinentais" (Declaração da XVI CRM, 2011). Um ano depois, decidiram formar outro grupo ad hoc para elaborar uma proposta regional voltada a enfrentar o "trânsito irregular" de migrantes cubanos para fora da região centro-americana (Declaração da XVII CRM, 2012). Posteriormente, o tema "fluxos migratórios extracontinentais" deu origem a um encontro em Washington, DC, organizado pela OIM, entre os cônsules dos Estados membros da CRM e os países de "origem", "trânsito" e "destino" (Declaração da XVIII CRM, 2013). A partir de 2011, os Estados membros da CRM modificaram sua estratégia para conter o movimento, buscando estabelecer relações de cooperação com a Conferência Sul-americana de Migrações (CSM) para enfrentar os fluxos migratórios continentais e extracontinentais (Ramírez; Ceja; Alfaro, 2019). Conforme afirmou o representante de Honduras por ocasião da Conferência Regional sobre Migração (RCM), realizada em 2016, a estratégia deveria "incluir a los países sudamericanos que son usados como puertas para entrar en la región".

O território mexicano é um centro nevrálgico da mobilidade migratória terrestre com destino aos Estados Unidos. Sua posição geográfica o tornou um país de intenso trânsito migratório da América Latina e Caribe para a América do Norte. A maioria desses migrantes são procedentes do chamado triângulo setentrional da América Central (Guatemala, Honduras e El Salvador), com 
a intenção de chegar aos Estados Unidos (Márquez Covarrubias, 2015; Varela Huerta, 2016; 2020; Riediger-Röhm, 2013). O México tornou-se não apenas um tático território de passagem migratória para a população centro-americana, mas também, por anos, de caribenhos e africanos que chegavam ao continente a partir do Equador, como mencionado anteriormente, através de um largo corredor conectando esses dois países. Diante desse cenário, o controle migratório implementado pelo governo mexicano, com forte presença dos Estados Unidos, revela a face mais brutal dos regimes de fronteira na América Latina e Caribe. A expansão e a intensificação das operações de controle, bem como a proliferação de centros de detenção ao longo de todo o território nacional fizeram com que o país ganhasse o notório título de fronteira vertical (Márquez Covarrubias, 2015; Varela Huerta, 2015; Villafuerte Solís; García Aguilar, 2015; TorreCantalapiedra; Yee-Quintero, 2018). Trata-se de uma fronteira expandida que tem início logo na fronteira meridional e segue os grandes grupos migratórios que adentram o país com destino aos Estados Unidos. Análises recentes sobre diversas práticas de controle migratório, em particular da migração "indocumentada", confirmam a "verticalidade fronteiriça" que tem assumido o território mexicano (Torre Cantalapiedra; Yee-Quintero, 2018). Como Wiesner e Basok (2020) indicam no artigo que compõe este dossiê, trata-se de um processo que vem ganhando duras medidas, embasadas no argumento de soberania e segurança nacional. Não por acaso, as autoras ressaltam que esse processo é intensificado entre o final da década de 1990 e início de 2000, período em que o México adere ao NAFTA. Márquez Covarrubias (2015) vai adiante e demonstra que, sob o discurso da "guerra às drogas", o governo estadunidense tem promovido a militarização no México. A partir de 2008, destinou três milhões de dólares para financiar e treinar militares, policiais e agentes de migração e noventa milhões de dólares foram dedicados ao Instituto Nacional de Migración $(\mathrm{INM})^{9}$, responsável pela prisão de migrantes indocumentados.

${ }^{9}$ Criado em 1993, é uma unidade do governo mexicano dependente da Secretaria do Interior que controla e supervisiona a migração no país. 
As diversas medidas estatais visando conter o movimento em zonas fronteiriças, implementadas nas últimas duas décadas, indicam uma transformação substantiva das concepções e práticas de controle de fronteiras. O processo de securitização da migração vivido no México incluiu a produção de uma narrativa de direitos humanos que foi questionada por organizações civis. Desde os primeiros anos da década de 2000, diversos planos e medidas intensas de vigilância migratória e deportação foram implementadas no território mexicano: o Plano Sur, em 2001, o Plano Mérida, em 2003, o Programa Integral Frontera Sur, em 2014, além dos memorandos de entendimento com Honduras, Guatemala e El Salvador, todos elaborados sob um discurso que "presume 'proteger' a los migrantes y 'ordenar el paso fronterizo' (Márquez Covarrubias 2015, p. 116). Ações punitivas empregadas por forças policiais, que envolvem detenções e deportações, até a implementação de medidas de dissuasão, como formas de impedir o embarque em trens de carga ${ }^{10}$, por meio de acordos com as companhias férreas para aumentar a velocidade do veículo ou intensificar a vigilância das malhas férreas são algumas das ações realizadas (RiedigerRöhm, 2013; Covarrubias, 2015). Nas palavras de Varela Huerta, trata-se de "un territorio convertido en un virtual tapón sangriento, mortal, para quienes intentan llegar a Estados Unidos" (Varela Huerta, 2015, p. 33). A produção de criminalização, as deportações e prisões produzem um sádico espetáculo que "evoca o fetiche da transgressão nos pontos de interceptação sempre crescentes em uma zona de fronteira amorfa onde as trajetórias dos migrantes podem ser interrompidas" a qualquer momento (De Genova 2013, p. 10). ${ }^{11}$

No entanto, no contexto de extrema violência e securitização da migração vivido no México, surgiram novas práticas de mobilidade humana

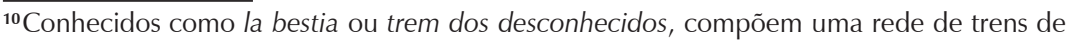
carga que atravessa o México em direção aos Estados Unidos.

${ }^{11}$ Contudo, tais práticas físicas de controle migratório não são as únicas produzidas nesse intenso enrijecimento fronteiriço vivido pelo México. O controle, assim como nos demais países até aqui discutidos, também se dá de forma legalizada e interna pelo Estado. Destacamos os programas de "regularização" ou "legalização" que ocorreram no final da década de 1990 e início de 2000 e que, no artigo de Wiesner e Basok (2020), neste dossiê, são explorados com maior acuidade.
} 
e mobilização política que se estabeleceram como "caravanas de migrantes". Estas particulares expressões de mobilidade fazem parte de uma nova tendência global de êxodo massivo de pessoas que cruzam as fronteiras internacionais (Castro Neira, 2019) e, ao mesmo tempo, constituem uma manifestação concreta das transformações pela qual atravessam os regimes fronteiriços das Américas do Norte e Central durante a última década. Com uma visibilidade incomum no final de 2018, o trânsito maciço de milhares de migrantes centro-americanos pelo México rumo aos Estados Unidos e as políticas implantadas para contê-lo deram origem a um "novo tipo de luta migrante" (Varela Huerta; McLean, 2019), que pode ser enquadrada nas chamadas "lutas pelo movimento".

Nessas novas expressões de luta migrante, o próprio movimento massivo de pessoas se combina com outras práticas de contestação que estabelecem seus protagonistas, a quem Sayad (2008) chama de migrantes heréticos. As caravanas de migrantes, como Varela Huerta e McLean (2019) alertaram, também envolveram ações de protesto como greves de fome, marchas e comícios perante agências intergovernamentais questionadas por sua cumplicidade ou inação, manifestações contra expressões de racismo, coletivas de imprensa ou boletins. Nesse sentido, a concentração de milhares de caravaneiros em frente aos escritórios do ACNUR na Cidade do México, em novembro de 2018, para solicitar meios de transporte em sua rota para o norte é um exemplo específico das práticas que desenvolvem com o propósito de aliviar seu deslocamento a pé e serem capazes de atingir o objetivo da rota traçada. Diante dessa demanda, dias após o presidente dos EUA, Donald Trump, anunciar medida que restringia o acesso ao asilo na fronteira sul dos Estados Unidos, o ACNUR, a OIM e o ACNUDH justificaram sua recusa em fornecer tal ajuda sob o argumento do alcance e das limitações estabelecidas pelos respectivos mandatos institucionais: "Ic]ualquier ayuda para el transporte de personas migrantes hacia un tercer país requiere del acuerdo previo o petición de los Estados involucrados"12.

12 "Precisiones respecto de los mandatos y trabajo en México del ACNUR, OIM y ONU$\mathrm{DH}^{\prime \prime}$, Cidade do México, 09 de novembro de 2018. 
O comunicado conjunto estabelecia, claramente, sua subordinação aos interesses estatais e as consequentes formas de contenção do movimento.

Essas caravanas de migrantes da América Central têm uma história que explica seu surgimento e a forma particular que assumiram. Tal fenômeno entrelaça processos e acontecimentos derivados de uma migração forçada originada nos países de origem e um trânsito terrestre moldado pela violência exercida por atores estatais e setores do crime organizado. As múltiplas formas de violência exercidas contra migrantes centro-americanos são distribuídas espacialmente em certas entidades federativas, bem como produzidas de diferentes maneiras, dependendo das especificidades do grupo social e/ou das instituições envolvidas (Castillo Ramírez, 2020). As origens das caravanas de migrantes surgidas em 2018 estão relacionadas às caravanas de mães centro-americanas e às chamadas Viacrucis migrantes como instâncias de denúncia e protesto de familiares de migrantes assassinados ou desaparecidos e um universo heterogêneo de defensores da mobilidade migratória fronteiriça (Castro Neira, 2019; París-Pombo; Montes, 2020; Varela Huerta; McLean, 2019). A modalidade da caravana é inspirada nas procissões religiosas da Viacrucis migrante: caminhada em massa e em plena luz do dia (Varela Huerta; McLean, 2019). Assim, os migrantes encontraram uma forma alternativa de transitar pelas estradas e rotas sujeitas ao controle dos agentes migratórios em conluio com uma ampla gama de atores que extraem ganhos econômicos de forma consensual, coercitiva ou extorsiva. Ao contrário das experiências anteriores de mobilidade coletiva, o "êxodo"13 que ocorreu entre o final de 2018 e o início de 2019 adotou características únicas em vista de seu volume, formas de organização e composição heterogênea. Nesse sentido, embora não seja um fenômeno novo, as caravanas de migrantes mais recentes constituíram uma experiência inédita de migração coletiva na região (París-Pombo; Montes, 2020). Elas modificaram a representação dominante da mobilidade humana no México: as caravanas substituíram as imagens da migração centro-americana

${ }^{13}$ As caravanas de migrantes centro-americanos, também, foram chamadas "êxodo" por diferentes atores, incluindo acadêmicos (París-Pombo; Montes, 2020). 
associadas exclusivamente a la bestia, a imagem paradigmática da migração "indocumentada" (París-Pombo; Montes, 2020).

Migrantes caravaneiros ${ }^{14}$, enquanto uma nova forma de transmigração (Varela Huerta; McLean, 2019), modificaram o regime de (in)visibilidade da migração em trânsito pelo corredor que se estende da América Central até a fronteira sul dos Estados Unidos. Ao longo de um corredor migratório altamente estratificado, securitizado e militarizado, atravessado por múltiplas violências e riscos para sustentar a vida, com experiências marcadamente desiguais para homens, mulheres e gêneros dissidentes, as caravanas se tornaram uma estratégia de mobilidade para migrantes expostos à brutalidade e à arbitrariedade do controle de fronteiras e do crime organizado. A visibilidade dada pelas caravanas aos migrantes centro-americanos, como sugerem París-Pombo e Montes (2020), desempenhou um papel fundamental nas chances de milhares deles de chegarem à fronteira norte, apesar das condições de violência prevalecentes. As estratégias utilizadas para tornar visível a mobilidade humana permitem reduzir os altos riscos associados ao ato de migrar através do México. De acordo com a sua proposição, "a visibilidade do êxodo centro-americano significou uma estratégia para enfrentar a violência contra os migrantes e a criminalização da mobilidade humana no México" (París-Pombo; Montes, 2020, p. 11).

\section{Considerações finais}

Migrações e regimes fronteiriços na América Latina e Caribe são dois temas que se movem conjuntamente. Todo o aparato burocrático e tecnológico envolvido na constituição dos regimes fronteiriços nesse continente, nas duas últimas décadas, é parte interconectada de um longo processo em escala global de proliferação de fronteiras, e que conta com a presença de governos e organizações internacionais, através de discursos punitivos e humanitários que mobilizam a noção de "crise" para ganhar

\footnotetext{
${ }^{14}$ Em espanhol, a expressão "caravanizar a migração" pode ter diferentes significados e usos: desde uma conotação relacionada com uma aposta política até um significado criminalizante (Varela Huerta; McLean, 2019).
} 
legitimidade e justificar intervenções estatais múltiplas e díspares contra a "migração irregular". Sobretudo após essa ampla "virada à direita", temas como "fronteiras nacionais", "securitização" e "ilegalidade" ganham maior legitimidade em discursos nacionalistas proferidos por autoridades governamentais. Vivemos e vivenciamos um mundo móvel no qual fronteiras proliferam-se via relações de poder assimétricas e a expansão e diversificação dos meios de controle e disciplinamento do movimento. Como foi destacado ao longo desse artigo, isso faz com que fronteiras não sejam estáticas, mas estejam em constante mutação. Sob o discurso de "crise" e "ajuda humanitária", fronteiras ganham velocidade e opacidade nesse mundo globalizado, com o intuito de "conter", "ordenar" e "regularizar" aqueles que atravessam territórios. Fronteiras avançam e retrocedem diante de corpos indesejados. É a busca incessante pela superação de toda e qualquer imprevisibilidade humana, capaz de colocar em risco um mundo cuja estabilidade parece depender exclusivamente de um precário e desigual equilíbrio econômico.

As reflexões desenvolvidas neste artigo demonstram como o estarno-mundo na condição de migrante é paradoxal. Os migrantes são excluídos politicamente, contudo, sua resistência, expressa por meio da própria migração e das lutas migrantes, os projeta ativamente na definição de políticas de controle de mobilidade. Enquanto campos de disputas desiguais, migrantes indocumentados experienciam provisoriedade, medo, precariedade, deveres, insultos e proibições. Regimes de fronteiras tornamse espaços de disputas para migrantes indocumentados. Documentos que comprovem legalidade são exigidos para se obter um trabalho, matricular filhos em escola, alugar uma habitação, ter direito a cuidados de saúde ou qualquer tipo de auxilio social. Em um mundo onde os discursos do transnacionalismo e da circulação global ganham tanta força, regimes de fronteiras revelam outra tessitura da globalização, menos pujante e inclusiva. Ela é, muitas vezes, burocrática e confusa, além de excludente (Dias, 2019).

Dessa forma, fronteiras são produtos e produtoras de vidas marginais. "Para algumas pessoas - todos os migrantes e pessoas que vivem ao longo 
das fronteiras - cruzar fronteiras é uma característica inescapável da vida; é um modo de estar no mundo" (Khosravi, 2010, p. 4) ${ }^{15}$. Sua "elasticidade tecnológica e governamental" determina quebras ou interrupção de conexões, além de vigilância território adentro. Fronteiras produzem a ilegalidade. Assim, se no sistema de Estado-nação migrantes indocumentados representam um elemento inquietante, pois quebram normas éticas e estéticas, sua resistência e presença lançam em crise a ficção original da soberania. A dinâmica da inclusão e exclusão torna-se regente em ambos os casos e, cruelmente, produz o que Ngai (2004) define como uma "teleologia normativa", um infindável - e, muitas vezes, ilusório - processo de admissão legal que se propõe a desdobrar em residência permanente e, por fim, na tão almejada cidadania ou direito de permanência.

Eduardo Domenech é doutor em Sociologia, pesquisador do Consejo Nacional de Investigaciones Científicas y Técnicas (CONICET) e professor da Faculdade de Ciências Sociais da Universidad Nacional de Córdoba, Argentina.

$\triangle$ edomenech@unc.edu.ar

Gustavo Dias é doutor em Sociologia, professor e pesquisador da Universidade Estadual de Montes Claros, e realiza estágio de pós-doutorado no Programa de Estudos Pós-Graduados em Ciências Sociais (PUC-SP).

$\triangle$ tentonidias@hotmail.com

${ }^{15}$ No original: "For some people - all kinds of migrants and people who live along borders crossing borders is an inescapable feature of life; it is a mode of being in the world." 


\section{Referências}

1. ACOSTA ARCARAZO, Diego; BLOUIN, Cécile; FREIER, Feline. La emigración venezolana: respuestas latinoamericanas. Documentos de Trabajo, n. 3 (2da. época), Madrid: Fundación Carolina, 2019.

2. ÁLVAREZ VELASCO, Soledad. From Ecuador to elsewhere: the (re)configuration of a transit country. Migration and Society, v. 3, n. 1, p. 34-49, 2020.

3. ÁLVAREZ VELASCO, Soledad. Ecuador-México-EE.UU.: la producción de una zona de tránsito entre políticas de control y la autonomía de la migración. In: CORDERO, Blanca; MEZZADRA, Sandro; VARELA HUERTA, Amarela (orgs.). América Latina en movimiento: migraciones, límites a la movilidad y sus desbordamientos. Madrid: Traficantes de Sueños / Tinta Limón / UACM, 2019. p. 63-97.

4. BASOK, Tanya. Regional migration and Argentina's "hospitality" in crisis. In: MENJÍVAR, Cecilia; RUIZ, Marie; NESS, Immanuel (orgs.). The Oxford handbook of migration crises. Oxford: Oxford University Press, 2019.

5. CASTILLO RAMÍREZ, Guillermo. Migración forzada y procesos de violencia: los migrantes centroamericanos en su paso por México. Revista Española de Educación Comparada, n. 35, p. 14-33, 2020.

6. CASTRO NEIRA, Yerko. Las caravanas de migrantes. Racismo y ley en los éxodos masivos de población. Iberoforum - Revista de Ciencias Sociales, v. 14, n. 27, p. 8-48, 2019.

7. CEJA, Iréri. Migraciones haitianas en la región andina. Andina Migrante, n. 19, p. 2-13, 2015.

8. CRM. Comunicado Conjunto. I Conferencia Regional sobre Migración. Puebla, México. 13-14 março, 1996.

9. CORDERO, Blanca; MEZZADRA, Sandro; VARELA, Amarela (orgs.). América Latina en movimiento: migraciones, límites a la movilidad y sus desbordamientos. Madrid: Traficantes de Sueños / Tinta Limón / UACM, 2019.

10. CORREA, Ahmed. Deportación, tránsito y refugio. El caso de los cubanos de El Arbolito en Ecuador. Périplos - Revista de Estudos sobre Migrações, v. 3, n. 2, p. 52-88, 2019.

11. DE GENOVA, Nicholas. Spectacles of migrant "illegality": the scene of exclusion, the obscene of inclusion. Ethnic and Racial Studies, v. 36, n. 7, p. 1180-1198, 2013.

12. DIAS, Gustavo. Mobilidade migratória: uma leitura crítica para além de metáforas hidráulicas. REMHU - Revista Interdisciplinar da Mobilidade Humana, v. 27, p. 61-78, 2019.

13. DIAS, Gustavo. Brazilian migration into London: mobility and contemporary borders. Tese (Doutorado em Sociologia). Goldsmiths College, University of London, 2016. 
14. DIAS, Gustavo; JAROCHINSKI SILVA, João Carlos; SILVA, Sidney. Travelers of the Caribbean: positioning Brasilia in Haitian migration routes through Latin America. VIBRANT - Virtual Brazilian Anthropology, v. 17, p. 1-19, 2020.

15. DOMENECH, Eduardo. La "política de la hostilidad" en Argentina: detención, expulsión y rechazo en frontera. Estudios Fronterizos, v. 21, e057, 2020.

16. DOMENECH, Eduardo. Contested spaces of mobility: the South American migration and border regime. In: First international workshop on contested territories, Escola de Geografia, Universidade de Leeds, Leeds, Reino Unido, 2019.

17. DOMENECH, Eduardo. Controle da imigração "indesejável": expulsão e expulsabilidade na América do Sul. Ciência e Cultura, v. 67, n. 2, p. 25-29, 2015.

18. DOMENECH, Eduardo; BOITO, Maria Eugenia. "Luchas migrantes" en Sudamérica: reflexiones críticas desde la mirada de la autonomía de las migraciones. In: CORDERO, Blanca; MEZZADRA, Sandro; VARELA, Amarela (orgs.). América Latina en movimiento: migraciones, límites a la movilidad y sus desbordamientos. Madrid: Traficantes de Sueños / Tinta Limón / UACM, 2019. p. 159-190.

19. DUFRAIX TAPIA, Roberto; RAMOS RODRÍGUEZ, Romina; QUINTERO ROJAS, Daniel. "Ordenar la casa": securitización y producción de irregularidad en el norte de Chile. Sociologias, v. 22, n. 55, p. 172-196, 2020. http://doi. org/10.1590/15174522-105689

20. DÜVELL, Franck. The globalisation of migration control. OpenDemocracy. Post original de 2003, republicado em 30 set. 2015. Disponível em: < http://www. opendemocracy.net/people-migrationeurope/article_1274.jsp>.

21. EL-SHAARAWI, Nadia; RAZSA, Maple. Movements upon movements: refugee and activist struggles to open the Balkan route to Europe. History and Anthropology, v. 30, n. 1, p. 91-112, 2019.

22. GANDINI, Luciana; PRIETO, Victoria; LOZANO ASCENCIO, Fernando. EI éxodo venezolano: migración en contextos de crisis y respuestas de los países latinoamericanos. In: GANDINI, Luciana; LOZANO ASCENCIO, Fernando; PRIETO, Victoria (orgs.). Crisis y migración de población venezolana: entre la desprotección y la seguridad jurídica en Latinoamérica. CDMX: Universidad Nacional Autónoma de México, 2019.

23. GRANJA, Lorena; VILLARREAL, Maria. Mercosur migrante: enfoques y evolución del tratamiento de la movilidad humana en el Mercosur. Terceiro Milênio - Revista Crítica de Sociologia e Política, v. 8, p. 49-78, 2017.

24. HESS, Sabine. De-naturalising transit migration. Theory and methods of an ethnographic regime analysis. Population, Space and Place, v. 18, n. 4, p. 428440, 2012.

25. HESS, Sabine; KASPAREK, Bernd. Under control? Or border (as) conflict: reflections on the European border regime. Social Inclusion, v. 5, n. 3, p. 58-68, 2017. 
26. KATZ, Claudio. Neoliberalismo, neodesarrolismo, socialismo. Buenos Aires: Batalla de Ideas, 2016.

27. KHOSRAVI, Shahram. The 'illegal' traveller: an auto-ethnography of borders. London: Palgrave Macmillan, 2010.

28. KRON, Stefanie. ¿Legitimidad política por despolitización de la migración? Una reflexión crítica del arreglo institucional de un nuevo régimen regional de migración en Norte y Centroamérica. In: KRON, Stefanie; COSTA, Sérgio; BRAIG, Marianne (orgs.). Democracia y reconfiguraciones contemporáneas del derecho en América Latina. Madrid / Frankfurt: Iberoamericana Vervuert, 2012. p. 387-404.

29. KRON, Stefanie. Gestión migratoria en Norte y Centroamérica: manifestaciones y contestaciones. Anuario de Estudios Centroamericanos, n. 37, p. 53-85, 2011.

30. LEITE, José C.; UEMURA, Janaina; SIQUEIRA, Filomena (orgs.). O eclipse do progressismo: a esquerda latino-americana em debate. São Paulo: Elefante, 2018.

31. MÁRQUEZ COVARRUBIAS, Humberto. No vale nada la vida: éxodo y criminalización de migrantes centroamericanos en México. Migración y desarrollo, v. 13, n. 25, p. 151-173, 2015.

32. MARTIGNONI, Martina; PAPADOPOULOS, Dimitris. Genealogies of autonomous mobility. In: ISIN, Engin; NYERS, Peter (orgs.). Routledge handbook of global citizenship studies. London: Routledge, 2014. p. 60-70.

33. MARTINS, Carlos Eduardo. Globalização, dependência e neoliberalismo na América Latina. São Paulo: Boitempo, 2013.

34. MÉNARD MARLEAU, Andrée. Ecuador como nodo articulador de la migración senegalesa en América del Sur. Migración y Desarrollo, v. 15, n. 29, p. 31-50, 2017.

35. MEZZADRA, Sandro. Derecho de fuga: migraciones, ciudadanía y globalización. Madrid: Traficantes de Sueños, 2005.

36. MEZZADRA, Sandro; NEILSON, Brett. Border as method, or the multiplication of labor. Durham: Duke University Press, 2013.

37. MINISTÉRIO DAS RELAÇÕES EXTERIORES - MRE. Declaração do Grupo de Lima. 05 jan. 2020. Disponível em: < http://www.itamaraty.gov.br/pt-BR/notas-aimprensa/21188-declaracao-do-grupo-de-lima-6 $>$.

38. MOHAR, Gustavo. Reflexiones sobre el grupo de Puebla en busca de un diálogo pendiente. Notas de Población, v. 28, n. 73, p. 253-272, 2001.

39. NGAI, Mae. Impossible subjects: illegal aliens and the making of modern America. Princeton: Princeton University Press, 2004.

40. ORGANIZACIÓN DE LOS ESTADOS AMERICANOS-OEA; ORGANIZACIÓN INTERNACIONAL PARA LAS MIGRACIONES - OIM. Flujos de migrantes en 
situación migratoria irregular provenientes de África, Asia y el Caribe en las Américas. Washington, D.C.: OEA/OIM, 2016.

41. ORGANIZACIÓN DE LOS ESTADOS AMERICANOS - OEA. Migración extrarregional en las Américas. Washington, D.C.: OEA, 2010.

42. ORGANIZACIÓN INTERNACIONAL PARA LAS MIGRACIONES - OIM. Plan para fortalecer la gobernanza de los flujos de migrantes extrarregionales en Mesoamérica. San José, Costa Rica: OIM, 2016.

43. PAPADOPOULOS, Dimitris; STEPHENSON, Niamh; TSIANOS, Vassilis. Escape routes control and subversion in the twenty-first century. London: Pluto Press, 2008.

44. PAPADOPOULOS, Dimitris; TSIANOS, Vassilis. After citizenship: autonomy of migration, organisational ontology and mobile commons. Citizenship Studies, v. 17, n. 2, p. 178-196, 2013.

45. PARÍS-POMBO, María Dolores; MONTES, Verónica. Visibilidad como estrategia de movilidad: el éxodo centroamericano en México (2018-2019). EntreDiversidades - Revista de Ciencias Sociales y Humanidades, v. 7, n. 1, p. 9-38, 2020.

46. PINASSI, Maria. Neodesarrollismo: uma parábola de ricos para pobres. In: FÉLIZ, Mariano; PINASSI, Maria. (org.). La farsa neodesarrollista y las alternativas em América Latina y el Caribe. Buenos Aires: Herramienta Ediciones, 2017.

47. RAMÍREZ, Jacques; CEJA, Iréri; ALFARO, Yolanda. La Conferencia Sudamericana de Migraciones y el Proceso Puebla: ¿entre la seguridad y los derechos? Périplos - Revista de Estudos sobre Migrações, v. 3, n. 1, p. 11-36, 2019.

48. RIEDIGER-RÖHM, Lara. ¿México: ruta de la muerte o camino hacia una vida mejor? Revista de Ciencias Sociales de la Universidad Iberoamericana, v. 6, n. 16, p.167-182, 2013.

49. SAYAD, Abdelmalek. Estado, nación e inmigración. El orden nacional ante el desafío de la inmigración. Apuntes de Investigación del CECYP, n. 13, p. 101116, 2008.

50. SCIORTINO, Giuseppe. Immigration in a Mediterranean welfare state: the Italian experience in comparative perspective. Journal of Comparative Policy Analysis - Research and Practice, v. 6, n. 2, p. 111-129, 2004.

51. SILVA, Sidney A. da. Imigração e redes de acolhimento. O caso dos haitianos no Brasil. Revista Brasileira de Estudos de População, v. 34, n. 1, p. 99-117, 2017.

52. SILVA, Sidney A. da. Fronteira amazônica: passagem obrigatória para haitianos? REMHU - Revista Interdisciplinar da Mobilidade Humana, v. 23, n. 44, p. 119-134, 2015.

53. SINGER, André. Os sentidos do lulismo: reforma gradual e pacto conservador. São Paulo: Companhia das Letras, 2012. 
54. TAZZIOLI, Martina. Which Europe? Migrants' uneven geographies and counter-mapping at the limits of representation. Movements - Journal for Critical Migration and Border Regime Studies, v. 1, n. 2, p.120, 2015.

55. TORRE-CANTALAPIEDRA, Eduardo; YEE-QUINTERO, José Carlos. México ¿una frontera vertical? Políticas de control del tránsito migratorio irregular y sus resultados, 2007-2016. LiminaR, v. 16, n. 2, p. 87-104, 2018.

56. TRABALÓN, Carina. Política de visado y regulación de las fronteras. Un análisis desde la movilidad de haitianos en Sudamérica. Polis - Revista Latinoamericana, v. 17, n. 51, p. 163-186, 2018.

57. VARELA HUERTA, Amarela. Luchas migrantes en contextos de tránsito migratorio, el caso del movimiento migrante centroamericano. REMHU - Revista Interdisciplinar da Mobilidade Humana, v. 24, n. 48, p. 31-44, 2016.

58. VARELA HUERTA, Amarela. "Luchas migrantes": un nuevo campo de estudio para la sociología de los disensos. Andamios - Revista de Investigación Social, v. 12, n. 28, p. 145-170, 2015.

59. VARELA HUERTA, Amarela; MCLEAN, Lisa. Caravanas de migrantes en México: nueva forma de autodefensa y transmigración. Revista CIDOB d'Afers Internacionals, n. 122, p. 163-185, 2019.

60. VILLAFUERTE SOLÍS, Daniel; GARCÍA AGUILAR, María del Carmen. Crisis del sistema migratorio y seguridad en las fronteras norte y sur de México. REMHU - Revista Interdisciplinar da Mobilidade Humana, v. 23, n. 44, p. 83-98, 2015.

61. WIESNER, Martha R.; BASOK, Tanya. "Legalidad ilegal" y precariedad: la perspectiva desde el sur de México. Sociologias, v. 22, n. 55, p. 74-103, 2020. http://doi.org/10.1590/15174522-101813

62. ZIBECHI, Raul; MACHADO, Decio. Os limites do progressismo: sobre a impossibilidade de mudar o mundo de cima para baixo. Rio de Janeiro: Ed. Consequência, 2017.

63. ZOLBERG, Aristide; SUHRKE, Astri; AGUAYO, Sergio. International factors in the formation of refugee movements. International Migration Review, v. 20, n. 2, p. 151-169, 1986.

64. ZUBRZYCKI, Bernarda. Migración senegalesa, irregularidad y gobernabilidad migratoria en la Argentina. In: TEDESCO, João Carlos; KLEIDERMACHER, Gisele (orgs.). A imigração senegalesa no Brasil e na Argentina: múltiplos olhares, Porto Alegre: EST Edições, 2017. p. 101-116.

Recebido: 22 out. 2020.

Aceito: 03 nov. 2020. 